\title{
Virtual Reality Exergames in Rehabilitation Program for Cerebral Palsy Children
}

\author{
Fairuz Rauf \\ Faculty of Communication, Visual \\ Art and Computing \\ Universiti Selangor \\ Malaysia
}

\author{
Ashri Abu Hassan \\ Fakulti Sosial Sains dan Asas \\ PICOMS International University \\ College \\ Malaysia
}

\author{
Zuraidy Adnan \\ Faculty of Communication, Visual \\ Art and Computing \\ Universiti Selangor \\ Malaysia
}

\begin{abstract}
Virtual reality is a technology that provides a sense of presence in a real environment with the help of 3D pictures and animations formed in a computer environment and enable the person to interact with the objects in that environment. In other words, VR described as an improved form of humancomputer interaction that allows the user to be part of and interact with a computer-generated environment. This research will study on the usage of technology into rehabilitation process for Cerebral Palsy children. Objectives of this research is to develop a computer games for Cerebral Palsy children. Testing and commissioning have been conducted in order to ensure the game is properly developed for the target group.
\end{abstract}

\section{Keywords}

Virtual Reality, Cerebral Palsy, computer games

\section{INTRODUCTION}

There is no universally accepted definition of Cerebral Palsy (CP). The International Workshop on Definition and Classification of Cerebral Palsy in 2007 was offered for international consensus and adoption for $\mathrm{CP}$ definition as follow, "Cerebral Palsy (CP) describes a group of permanent disorders of the development of movement and posture, causing activity limitation, that are attributed to nonprogressive disturbances that occurred in the developing fetal or infant brain. The motor disorders of cerebral palsy are often accompanied by disturbances of sensation, perception, cognition, communication, and behaviour, by epilepsy, and by secondary musculoskeletal problems". The prevalence of CP range from 2 to 2.5per 1000 births worldwide (Mohammad, 2006; Rosen \& Dickinson, 1992; Odding, Roebroeck,\& Stam, 2006). It is the most common motor disorders in childhood (Capute \& Accardo's, 2008). In 2011, they were 170 CP cases reported and represented $7.6 \%$ of the total registration of children with special need in Malaysia (Ministry of Health Malaysia [MOH], 2011). It was increased by $26.5 \%$ (215 cases) in 2012.

It has been estimated that about $80 \%$ of children with $\mathrm{CP}$ have some type of movement disorder (Delgado, \& Albright, 2003). $\mathrm{CP}$ can be categorized according to the types of topographic motor involvement. It is including monoplegia, diplegia, hemiplegia, triplegia, quadriplegia, and double hemiplegia (Mohammad, 2006). Rehabilitation for children with cerebral palsy is not a "fix" but rather should focus on developing function (Novak, 2014). Recent systematic review evidence recommended that the interventions would address the family's goals and standard care for children with $\mathrm{CP}$ should include the following suite of interventions (1) casting for improving ankle range of motion for weight bearing and/or walking; (2) hip surveillance for maintaining hip joint integrity; (3) bimanual training, constraint-induced movement therapy, contextfocused therapy, goal-directed/functional training, and/or home programmes for improving motor activities or self-care function; (4) BoNT, diazepam, or selective dorsal rhizotomy for spasticity management; (5) fitness training for aerobic fitness; (6) pressure care for reducing the risk of ulcers; (7) bisphosphonates for improving bone mineral density; and (8) anticonvulsants for managing seiures (Novak et al., 2013). Rehabilitation program should be designed at the activities and participation level that put the point on the child's strengths and reflect their interests and motivations, and ultimately seek to help children live an inclusive and contented life (Novak et al., 2013). Child-active rehabilitation approaches is one of the contemporaneous management approaches of $\mathrm{CP}$ (Novak, 2014). The others including (1) compensatory and environment adaptation and (2) health and secondary prevention approaches. Child-active approaches are the new best-practice where the child is actively practicing real-life tasks during intervention, for improving or consolidating functional skill that they want to learn (Novak, 2014). Child-active approaches are in line with current neuroscience evidence about inducing maximal neuroplasticity, and these learning-based approaches include the following features: goal-based, taskspecific practice, high-dose repetition, use-dependent plasticity, experience-dependent plasticity, and learning-dependent plasticity (Novak, 2014).

New tools that is crop up for rehabilitation where its allows individuals to experience and interact with computer-generated environments through their senses, including vision, touch and/or hearing is virtual reality (Levin, 2011). Using virtual reality in rehabilitation was reportedly improved balance when standing, better hand control, and enhanced "fitness" Fehlings, 2001). Many CP children also report that they enjoy the competitive aspect of beating their previous scores in the VR activities (Fehlings, 2001)

Virtual reality (VR) technology is rapidly becoming a popular application for physical rehabilitation and motor control research. But questions remain about whether this technology really extends our ability to influence the nervous system or whether moving within a virtual environment just motivates the individual to perform. Virtual Reality technology has been commercially from the oil and gas industry to manufacturing (especially airplanes and cars), to military and medical care. In Medicine, VR has been used in teaching anatomy, training in diagnostic procedures (such as virtual colonoscopy, or virtual bronchoscopy), teaching open and minimallyinvasive surgery procedures, and in rehabilitation. Referring to Baram (2006) in his study about Virtual reality cues for improvement of gait in patients with multiple sclerosis, VR assisted methods of 
rehabilitation have been devised to assess and treat both cognitive deficits and motor disorders. Kawasaki (2006) also conclude that VR environment has been introduced to make the training enjoyable and improve better in healing process. This statement also supported by Matthew et al (2011) in their statement, "Activity-promoting gaming systems may encourage activity (especially in sedentary individuals) and complement rehabilitation".

New technologies like VR play an important role in functional training and performance. VR allows intensive and motivational training. It enables the use of many interactive environments and multiple sensory feedbacks. The use of this technology in disabled individuals ensures communication with others, improves social relations, and increases independence. VR meets important criteria for motor learning and motor control. VR applications also enable the therapist to train the child at home without supervision from the expert. High levels of motivation, participation, and cooperation are essential components of a game system. These characteristics of the training support behavioral changes and neural plasticity. VR implementation in children with CP positively affects brain reorganization, plasticity, motor capacity, visual perceptive skills, social participation and personal factors. Some of the benefits of using Virtual Reality in rehabilitation are it increases the $\mathrm{CP}$ children motivation, it can demonstrate target-directed functions more realistically, provide an experience for the child according to his/her own motor learning capacity and provide interactive treatment security systems work on the same basic principle of securing entry points of doors and windows, as well as interior space.

\section{OVERVIEW}

\subsection{Problem Statement}

One word comes to mind about rehabilitation is boring. Indeed, rehabilitation traditionaly is repetitive, and repetition tends to reduce patient's motivation. Another characteristic is the predominance of simple mechanical devices with little or no computerized sensing. Thus there are errors in interpreting evaluation data because there are no widespread online databases. Traditional rehabilitation is done one-to-one, meaning one therapist (or sometimes several) working with one patient. Thus costs are high, especially for demanding patients such as those with traumatic brain injury or spinal chord injury. For the portion of therapy that the patient is doing at home, there currently is no monitoring. This results in varying degrees of compliance with the prescribed exercise regimen, and a larger than necessary variability in treatment outcome.

\subsection{Objectives}

The main objectives of this project are:

a) To identify the virtual reality development framework that suitable for cerebral palsy rehabilitation process for children.

b) To develop an exergame using VR technology for cerebral palsy rehabilitation.

\subsection{Scope and Limitations}

Scope for this project includes:

a) This research focus on children patient with cerebral palsy known as spastic hemiplegia, one side of the body is affected, usually the arm more than the leg. The focus group on type of $\mathrm{CP}$ is the mild $\mathrm{CP}$ which is the first category that not severe.
The virtual reality game only addresses the ways in which upper limbs and memories are improved.

b) In this research, user will be able to control the environment by using the head mount display (HMD) and the controller configurations will be input by Oculus Touch controllers. It involves hands movement and gestures for the movements of their head that can be transmitted into the game.

c) For the system development, this research focus on VR game for CP children. The research focus on five stages for patient to play.

\section{LITERATURE REVIEW}

Since the first time the term "Virtual Reality" (VR) has been used back in the 60s, VR has evolved in different manners becoming more and more like the real world. The former is a computer-based environment that can simulate places in the real or imagined worlds. In the past, there was a major difficulty about using equipment such as a helmet with goggles, while now new devices are being developed to make usability better for the user. VR, which is based on three basic principles: Immersion, Interaction, and User involvement with the environment and narrative, offers a very high potential in education by making learning more motivating and engaging (Laura and Freina, 2015).

Based on (Upadhyay and Khandelwal, 2018), shows that VR's hardware, content and apps are more realistic and immersive, leading to increased visibility and popularity. VR learning imitates genuine employment and trainees do better at their real employment with immersive knowledge. VR is used to train, transform and enhance its dynamics, immersion, commitment, affordability, and remote accessibility. Use of virtual reality technology to promote and provide new method possibilities for greater education schooling and learning. In addition to defining the potential obstacles to adopting VR, this paper is designed to identify student opinions on the implementation of VR technology within their degree programmes, from a teaching method angle (Baxter and Hainey, 2019).

Games, which are on social networking platforms, have their own features, which distinguish them from other digital games. The study wants to explore social and social game variables and their role in enhancing the thrill of being felt. It also examines the relationship between perceived pleasure, subject matter, critical mass considered, playful intentions and actual behavior (Chen, Lu, \& Wang, 2016). Research in games and learning diverged into "games for learning" and "games as learning." Study wants to provide a third framed ' Learning games ' that can assist people deal with lived experiences outside of formal, educational environments with these media (Duncan, 2016). In certain fields of formal education, gamebased learning was very effectively used. The use of games in education and learning is increasing. The specific aims are to assess the effectiveness of the game as a teaching process, explore student learning experience, preference and motivation to participate in the game, and identify the connection between game and the learning experience of students and overall satisfaction (Oo \& Lim, 2016).

In developed countries, strokes are the most prevalent cause of adult long-term disability. Continued involvement in rehabilitation may relieve some of the effects and help stroke patients recover. Physical rehabilitation, however, requires a long commitment to tedious practice routines that often cause patients to give up such a therapeutic approach. In this sense, 
the rehabilitation of the stroke based on games can tackle two significant obstacles: rehabilitation accessibility and patient motivation (Kamkarhaghighi, Mirza-Babaei, El-Khatib, and Gerling, 2017). Study describes a fresh strategy, which takes complicated medical, food and activity data and provides it to diabetic patients through a mobile app / game that makes this complicated information more available by using interactive $3 \mathrm{D}$ computer graphics and playing. Pilot randomized outcomes of the control research showed that the use of interactive 3D games by Diabetes Visualizer improves participants 'knowledge of the situation and their daily management. Increased the interest of and willingness to participate with diabetes management was also stimulated by the Diabetes Visualizer application (Patterson, 2014).

The use of video games in rehabilitation is becoming more popular to clinicians. These games are embedded in off-theshelf commercial entertainment applications or especiallydeveloped for clinical purposes. Treatment of CP children is a challenging task for clinicians. Lack of motivation and progress monitoring are two important factors clinicians need to deal with. The use of serious games (SG), sometimes referred to as Virtual Rehabilitation (VR), could therefore be an interesting adjuvant to conventional treatment for these patients. This is however a new discipline and many scientific issues remain to be solved (Bonnechère, Jansen, Omelina, Degelaen, Wermenbol, 2014).

Rehabilitation programs for people with $\mathrm{CP}$ are increasingly using virtual reality environments for improving engine practice with increasing accessibility to computer-aided technology. Therefore, it is essential to consider whether improving efficiency in the virtual setting generalizes to the natural setting. However, these improvements have been particular to the setting in practice, no transfer has been made of learning. It concludes that it should not be taken for granted, but should be closely regarded, to application of virtual settings for engine rehabilitation in people with $\mathrm{CP}$ (Monteiro, Massetti, Silva, Kamp, Abreu, 2014).

\section{METHODOLOGY}

This Research methodology is a gathered data and information about a specific topic or object. In other word, Study is the systematic investigation of new topic or issue to review other present understanding by finding fresh facts. This section will clarify the details of the methodology used to complete this project. The ADDIE Model is the best methodology to make full use of this project. The ADDIE model is the generic method that educational designers and training developers have traditionally used. The five stages of Analysis, Design, Development, Implementation, and Evaluation are a vibrant, flexible guideline to build efficient instruments for coaching and performance support. Although perhaps the most popular design model, the ADDIE model has several weaknesses that have resulted in a number of spinoffs or variants. Figure 1 shows the ADDIE model method.

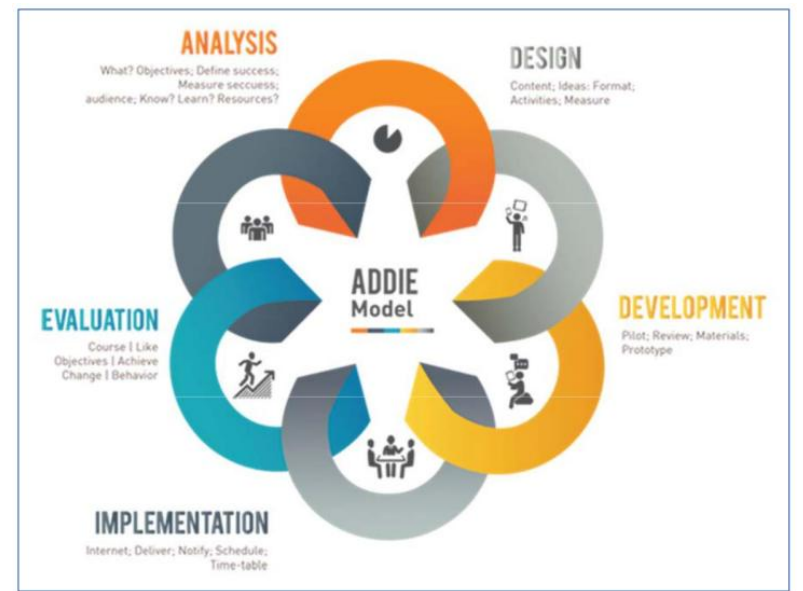

Figure 1: ADDIE Model Method

(Hidayanto et al, 2017)

\subsection{Analysis}

The analysis phase clarifies the educational issue, establishes the main objectives and identifies the understanding to help this CP people and analyse their abilities. The project developer then observes the $\mathrm{CP}$ children and interviews expertise to gather extra user information to enhance the project and make it more user-friendly. Then analyses are made of the gathered information

\subsection{Design}

This stage describes additional details about the CP children's VR game. The main interface for the game, the logo and the button to be used in the game is the design for this project. The storyboard method is used to show the game design because the design can be understood by storyboard. It is simple and not complicated to produce the framework, which guarantees that the user interacts without problems. There are few sound effect and background music added to make the user feels immerse and enjoy the environment.

\subsection{Development}

Production is begun in this stage. The first thing to do when creating Virtual Reality is to build the fundamental 3D model by using Autodesk Maya for the balloon and blocks designs. The model will then transfer to Unity 3D to create the VR environment. Developer will create the environment as well as applying music and sound effect to help user interact with the environment.

\subsection{Implementation}

Testing the prototype with the user to make sure the project has no mistakes come to this stage. The project will be test by the CP children to know their opinions. Implementation is an important step in the ADDIE process, as the data will be transmitted to the user during this phase.

\subsection{Evaluation}

In the evaluation phase, it involves the process of evaluating the VR for CP children game that was developed. Evaluation process is done by gathering feedback from the user which is the $\mathrm{CP}$ children and the trainer/parents who will help the $\mathrm{CP}$ with the device. This is the phase developer must react to the feedback to improve the project's quality.

\section{ANALYSIS}

Based on (Stake, 1995), qualitative data consist of words, observations, pictures, and symbols. Qualitative Data Analysis (QDA) refers to the processes and procedures that 
are used to analyze the data and provide some level or explanation, understanding, or interpretation. Qualitative data analysis typically occurs simultaneously with the data collection.

Observation and interviews are some of the of the way to gather data. Pemulihan Dalam Komuniti (PDK) Tanjong Karang is a place that have one of the CP children, so the observations start here. Puan Ida Hasni, UITM Puncak Alam physiotherapy lecturer is the person that can help the development of this project. This project observation process take place at PDK Tanjong Karang, Selangor. There are currently one CP children and one CP adult in the PDK. Children that have CP issues here in PDK Tanjong Karang have movement problems at their upper limb that consists of elbow, wrist and hand rotation and movement.

Questionnaires is a way is used to collect the data and information from the respondents. The questionnaires were delivered to the respondents which is parents of CP children by using google form and the respondents will answer the question in the developer device. The total of respondents that has been choose in this project was 10 respondents that already been submitted by respondent.

Do you want Your child to play and exercise their movement at the same time using VR?

10 responses
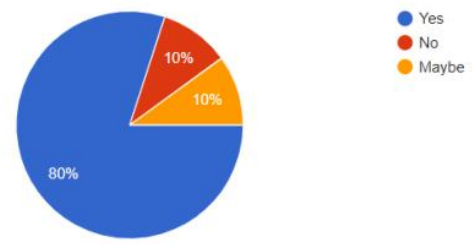

Figure 2: Percentage of parents willing to adapt using VR for rehabilitation

Would you like to have this VR game for your child?

10 responses
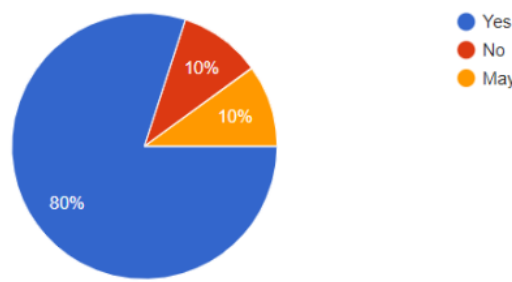

Maybe

Figure 3: Acceptance of technology

Figure 2 and 3 shows that most parents willing to adapt in using technology for rehabilitation purposes.

\section{DESIGN}

Figure 4 shows the flow chart of the game that is design for children with $\mathrm{CP}$.

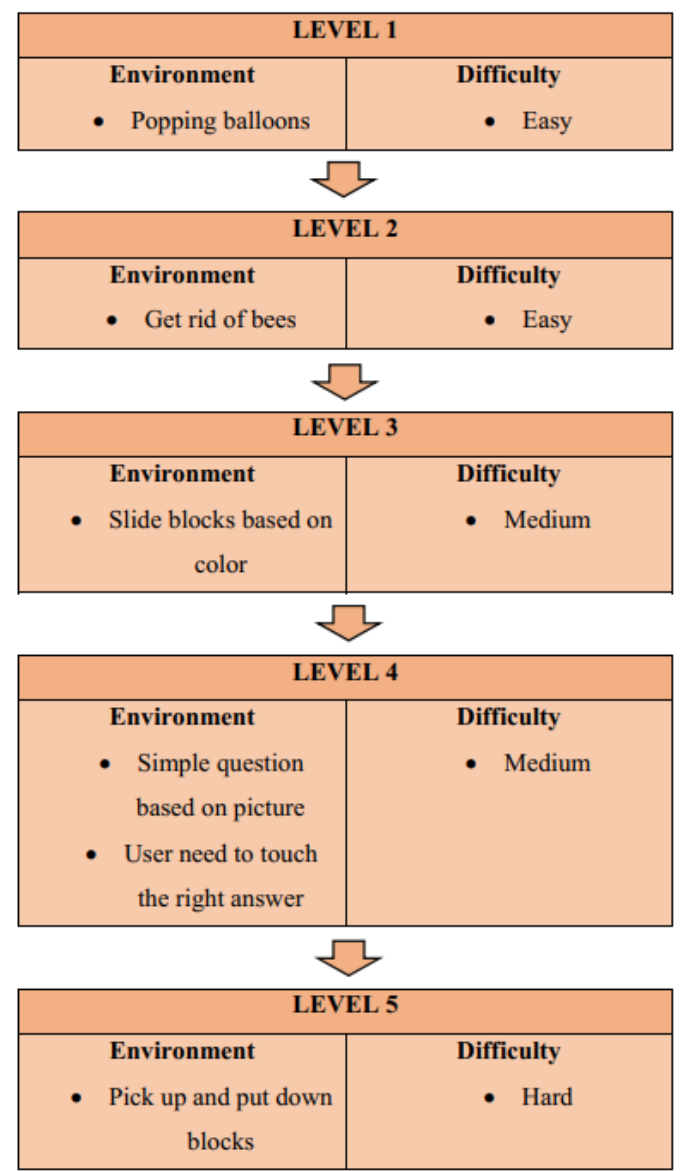

Figure 4: Flow chart of the game

Flowchart is used to show the levels implemented in the games that increase the game difficulty at each level in this project. Each level has its various difficulties and make the game become more challenging. The design that must have to develop this project is main menu interface, interface of the game, model and button for the game project. Sound effect and background music then applied for user's entertainment and feel the 3D environment. This design can attract user to play it simultaneously. This project consists 5 levels/stages for the user to interact.

\section{CONCLUSION}

This research can be extended in future in terms of application for other disabilities. Game that has been design can assist in rehabilitation process especially for patient with Cerebral Palsy.

\section{REFERENCES}

[1] Baram, Y., and Miller, A. (2006). Virtual reality cues for improvement of gait in patients with multiple sclerosis. journal of the American Academy of Neurology. (66) 178-181.

[2] Kasawaki, H. (2006). Hand rehabilitation support system based on self-motion control, with a clinical case report. World Automation Congress. Budapest, Hungary. July 24-26 2016

[3] Taylor, M., McCormick, D., Shawis, T., Impson, R., and Griffin, M. (2011). Activitypromoting gaming systems in exercise and rehabilitation. Journal of Rehabilitation Research \& Development, vol. 48 Number 10, 2011, p 1171- 1186 
[4] Virtual Reality in Rehabilitation of Children with Cerebral Palsy, Mintaze Kerem Gunel, Ozgun Kaya Kara, Cemil Ozal and Duygu Turker. Book chapter. https://cdn.intechopen.com.

[5] The definition and classification of cerebral palsy. (2007) Dev Med Child Neurol;49:1.

[6] Capute and Accardo's. (2008). Neurodevelopmental Disabilities in Infancy and Childhood, 3rd Ed. Publishing Co, Baltimore.

[7] Odding, E., and Roebroeck, M.E. (2006). The epidemiology of cerebral palsy: incidence, impairments and risk factors. Disabil Rehabil;28:183-91.

[8] Capute and Accardo's. (2008). Neurodevelopmental Disabilities in Infancy and Childhood, 3rd Ed. Publishing Co, Baltimore. 22

[9] Rosen, M.G. \& Dickinson, J.C.(1992). The incidence of cerebral palsy. Am J Obstet Gynecol; 167: 417-423.

[10] Delgado, M.R. \& Albright, A,L. (2003). Movement disorders in children: definitions, classifications, and grading systems. Journal of Child Neurology. S1-8.

[11] Novak, I., McIntyre, S., Morgan, C., Campbell, L., Dark, L., Morton, N., Stumbles, E., Wilson., S.A., \& Goldsmith, S. (2013). A systematic review of interventions for children with cerebral palsy: state of the evidence. Developmental Medicine \& Child Neurology. 877-878.

[12] Mohammed, M. J., (2006). Cerebral Palsy: Comprehensive Review and Update Annals of Saudi medicine, 26,(2,) 123-32.

[13] Novak, I. (2014). Evidence-Based Diagnosis, Health Care, and Rehabilitation for Children With Cerebral Palsy. J Child Neurol, 29: 1141.

[14] Levin, M.F. (2011). Virtual Reality: Rehabilitation Applications In Children With Disabilities. Childhood Disabilities Link, Summer 2011.

[15] Baxter, G., \& Hainey, T. (2019). Student perceptions of virtual reality use in higher education. Journal of Applied Research in Higher Education, JARHE-06-2018-0106. https://doi.org/10.1108/JARHE-06-2018-0106

[16] Bay, R. (2014). Cerebral palsy is lighting up the world | World CP Day. Retrieved August 5, 2019, from https://worldcpday.org/our-

campaign/publicawareness/cerebral-palsy-is-lighting-upthe-world/

[17] Berkman, M. I. (2018). History of Virtual Reality. In Encyclopedia of Computer Graphics and Games (pp. 19). https://doi.org/10.1007/978-3-319-08234-9_169-1

[18] Bonnechère, B., Jansen, B., Omelina, L., Degelaen, M., Wermenbol, V., Rooze, M.,Van Sint Jan, S. (2014). Can serious games be incorporated with conventional treatment of children with cerebral palsy? A review. Research in Developmental Disabilities, 35(8), 18991913. https://doi.org/10.1016/J.RIDD.2014.04.016

[19] Brockwell, H. (2016). Forgotten genius: the man who made a working VR machine in 1957: Page 2 | TechRadar. Retrieved from Tech Radar website: https://www.techradar.com/news/wearables/forgottengenius-the-man-who-made-aworking-vr-machine-in-

\section{$1957-1318253 / 223$}

[20] CerebralPalsy.org. (n.d.). Types of Cerebral Palsy Forms of CP |CerebralPalsy.orgCerebralPalsy.org. Retrieved August 5, 2019, from https://www.cerebralpalsy.org/about-cerebralpalsy/types-and-forms

[21] Chen, A., Lu, Y., \& Wang, B. (2016). Enhancing perceived enjoyment in social games through social and gaming factors. Information Technology \& People, 29(1), 99-119. https://doi.org/10.1108/ITP-07-20140156

[22] Cipresso, P., Giglioli, I. A. C., Raya, M. A., \& Riva, G. (2018). The Past, Present, and Future of Virtual and Augmented Reality Research: A Network and Cluster Analysis of the Literature. Frontiers in Psychology, 9, 2086. https://doi.org/10.3389/fpsyg.2018.02086

[23] de Mello Monteiro, C. B., Massetti, T., da Silva, T. D., van der Kamp, J., de Abreu, z. L. C., Leone, C., \& Savelsbergh, G. J. P. (2014). Transfer of motor learning from virtual to natural environments in individuals with cerebral palsy. Research in Developmental Disabilities, $35(10)$, 2430-2437. https://doi.org/10.1016/J.RIDD.2014.06.006

[24] DesignCrowd. (2016). Differences Between Logos and Icons. Retrieved June 30, 2019, from https://blog.designcrowd.co/article/353/differencesbetween-logos-andicons?culture $=$ en

[25] Duncan, S. C. (2016). "Games with learning": adpositions and the lusory attitude. On the Horizon, 24(3), 246-256. https://doi.org/10.1108/OTH-04-20160020

[26] Grace, L. (2005). Game Type and Game Genre Game Type. Retrieved from http://aii.lgracegames.com/documents/Game_types_and_ genres.pdf

[27] Houlihan, C. M. (2014). Bone health in cerebral palsy: Who's at risk and what to do about it? Journal of Pediatric Rehabilitation Medicine, 7(2), 143-153. https://doi.org/10.3233/PRM-140283

[28] Joe Bardi. (2019). What is Virtual Reality? VR Definition and Examples | Marxent. Retrieved August 5, 2019, from https://www.marxentlabs.com/what-isvirtualreality/

[29] Jon. (2017). 3 Benefits of Virtual Reality - LiveTiles. Retrieved July 5, 2019, from https://www.livetiles.nyc/3benefits-virtual-reality 2425

[30] Kamkarhaghighi, M., Mirza-Babaei, P., El-Khatib, K., \& Gerling, K. M. (2017). Architecture guideline for gamebased stroke rehabilitation. World Journal of Science, Technology and Sustainable Development, 14(2/3), 228 240. https://doi.org/10.1108/WJSTSD-06-2016-0039

[31] Laura Freina, M. O. (2015). (PDF) A Literature Review on Immersive Virtual Reality in Education: State Of The Art and Perspectives. Retrieved July 8, 2019.

[32] Maples-Keller, J. L., Bunnell, B. E., Kim, S.-J., \& Rothbaum, B. O. (2017). The use of Virtual Reality Technology in the Treatment of Anxiety and Other Psychiatric Disorders. Harvard Review of Psychiatry, 25(3),

103-113 
https://doi.org/10.1097/HRP.0000000000000138

[33] Marion Stanton. (2012a). Understanding cerebral palsy : a guide for parents and professionals - Ghent University Library. Retrieved July 5, 2019, from Jessica Kingsley Publishers website: https://lib.ugent.be/catalog/rug01:002150118\#referencedetails

[34] Marion Stanton. (2012b). Understanding Cerebral Palsy: A Guide for Parents and Professionals - Marion Stanton Google Books.

[35] Mauer, A. (2017). How to Explain Cancer to a Child and the Effects of Coloring Therapy in Children with Cancer. Retrieved

from https://digitalcommons.butler.edu/ugtheses

[36] Oo, B. L., \& Lim, B. T.-H. (2016). Game-based learning in construction management courses: a case of bidding game. Engineering, Construction and Architectural Management, 23(1), 4-19. https://doi.org/10.1108/ECAM-02-2015-002926
[37] Patterson, D. (2014). Using Interactive 3D Game Play to Make Complex Medical Knowledge More Accessible. Procedia Computer Science, 29, 354-363. https://doi.org/10.1016/J.PROCS.2014.05.032

[38] Rosenthal, R., Gantert, W. A., Hamel, C., Metzger, J., Kocher, T., Vogelbach, P., Hahnloser, D. (2008). The future of patient safety: Surgical trainees accept virtual reality as a new training tool. Patient Safety in Surgery, 2(1), 16. https://doi.org/10.1186/1754-9493-2-16

[39] Shelly DeButts. (2015). Playing Sports with Cerebral Palsy | My Life Without Limits. Retrieved August 5, 2019, from

[40] Smithers-Sheedy, H., Badawi, N., Blair, E., Cans, C., Himmelmann, K., KrägelohMann, I., ... Wilson, M. (2014).

[41] Stake, R. (1995). Issue-Based Observation Form for Case Studies in Science Education. Retrieved from https://legacy.oise.utoronto.ca/research/fieldcentres/ross/ ctl1014/Stake1995.pdf 